\section{Announcing a New Article Series: Perspectives on Value}

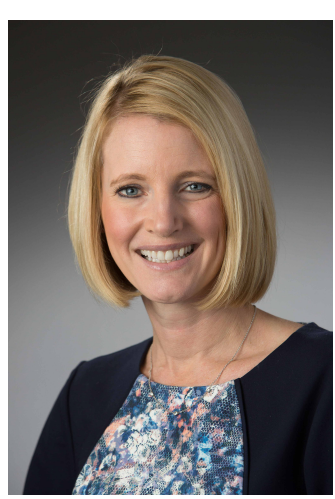

With the January 2019 issue, the Journal of Managed Care $\&$ Specialty Pharmacy (JMCP) is launching a new article series called Perspectives on Value. For this series, JMCP will publish a summary of a recent evidence report written by the Institute for Clinical and Economic Review (ICER), ${ }^{*}$ and a commentary authored by a key stakeholder will accompany each ICER summary. Dr. Robert Navarro, Assistant Editor, is curating this new section.

\section{Why Is JMCP Launching This New Series?}

1. Payers are referring to ICER reports in decision making. Whether and to what extent payers use ICER evidence reports has been the subject of debate, with market research reporting 29\%-79\% utilization. ${ }^{1-3}$ However, recent media headlines reduce doubt and affirm that payers are increasingly looking to these cost-effectiveness thresholds. In August 2018, CVS Caremark announced that it would allow clients to exclude drugs that exceed a cost-effectiveness ratio of $\$ 100,000$ per quality-adjusted life-year as determined by ICER, although it remains to be seen how that will be operationalized. Beyond this high-profile case, there are several examples of public and private plans using ICER reports to negotiate prices with pharmaceutical manufacturers, such as the Express Scripts/Sanofi/Regneron contract for Praluent. ${ }^{4}$

2. The discourse does not end with the ICER report. Since the media has covered payer use of ICER reports, a robust dialogue about the application of ICER value thresholds has ensued. Patient advocacy groups frequently and vocally warn that increased adoption of a cost-effectiveness standard will harm patient access to necessary medications. In September 2018, Robert Dubois, from the National Pharmaceutical Council, asserted that the CVS Caremark move was "too much, too soon," while Forbes contributor Joshua Cohen postulated that ICER could become America's NICE (National Institute for Clinical and Economic Excellence). 5,6 The inclusion of an accompanying commentary from a thought leader in a related area provides a first-hand account of the challenges

*ICER is an independent and nonpartisan research organization that objectively evaluates the clinical and economic value of prescription drugs, medical tests, and other health care and health care delivery innovations. ICER's analyses of new drug products result in a value-based price benchmark to reflect long-term effects on patient outcomes and a short-term budget impact of new drugs for policy and budget planning. More information is available at: https://icer-review.org/. and realities of applying (or not) the thresholds found in ICER evidence reports.

3. Manufacturers are actively engaging in cost-effectiveness benchmarks. Manufacturers of the products evaluated in ICER assessments are most commonly involved in the methodology via stakeholder meetings and public comments. Further, a recent survey of manufacturers reported that they are becoming more proactive by integrating ICER considerations into their evidence generation and market access strategies. ${ }^{7}$ Increasing exposure to summaries of the ICER evidence reports and providing thoughtful commentaries will aid manufacturers as they develop pricing strategies that incorporate product value.

4. Payers read JMCP. According to the Managed Care 2018 Media Measurement Study on readership by Kantar Media, JMCP ranks in the top 2 publications in measures of highest readers per average issue and exposures on average per page among clinical decision makers surveyed. Simply stated, JMCP is putting the data and information that payers want in the journal they read.

\section{What About Other Perspectives on Value?}

Today, there is no single authority on cost-effectiveness recognized by all payers in the United States as exists in other countries. However, the landscape is changing. The rapid acknowledgment of the ICER cost-effectiveness thresholds has been accompanied by the growth of other entities conducting cost-effectiveness work, such as the Innovation and Value Initiative. Without question, however, ICER is mature in its lifecycle, and it publishes reports with a specified plan and cadence. Although this new article series focuses on ICER evidence reports, JMCP will continue to monitor topics related to value that are of high interest to its readership.

\section{Who Will Author the Accompanying Stakeholder Commentaries?}

The accompanying commentaries from a stakeholder perspective are designed to advance the discourse beyond the publication of ICER summaries. Although only a single commentary will be published with each summary, over time JMCP aims to have a wide range of perspectives reflected in this series. Invited authors will come from leading academic centers, health plans, government agencies, pharmaceutical manufacturers, pharmacy benefit managers, and patient advocacy groups.

\section{Editor's Perspective}

On behalf of JMCP's editorial staff and advisory board, I am pleased to announce this addition to our scope of content. 
As the premier journal for managed care pharmacists, we are connecting the authors and investigators of cost-effectiveness research with the very people who are using this information to inform decisions. We are confident that this content will advance JMCP's mission of improving the quality of care delivered to patients served by managed care pharmacy and optimizing the value of pharmaceutical products and services.

\section{Laura E. Happe, PharmD, MPH}

Editor-in-Chief

lhappe@jmcp.org

\section{REFERENCES}

1. Schafer J, Galante D, Shafrin J. Value tools in managed care decision making: current hurdles and future opportunities. J Manag Care Spec Pharm. 2017;23(Suppl 6-a):S21-S27. Available at: https://www.jmcp.org/ doi/10.18553/jmcp.2017.23.6-a.s21.
2. America's Health Insurance Plans. Survey on use of comparative effectiveness studies. Available at: http://icer-review.org/wp-content/ uploads/2017/02/Summary-Findings-of-AHIP-Survey-on-Use-of-CER_ Jan2017.pdf. Accessed November 13, 2018.

3. Tennant L, Gittings K, Migliaccio-Walle K, Campbell C, Danavar A, Kanaskar A. Payer perceptions and utilization of the Institute for Clinical and Economic Review (ICER) value assessment framework. Poster presented at: International Society of Pharmacoeconomics and Outcomes Research, 22nd Annual International Meeting 2017; May 20-24, 2017; Boston, MA.

4. Miller S. This is how you do value-based care. Express Scripts. May 1, 2018. Available at: http://lab.express-scripts.com/lab/insights/industryupdates/this-is-how-you-do-value-based-care. Accessed November 13, 2018.

5. Cohen J. Will CVS Caremark make ICER the American NICE?

Forbes. September 20, 2018. Available at: https://www.forbes.com/sites/ joshuacohen/2018/09/20/will-cvs-caremark-make-icer-the-americannice/\#1c63ab366173. Accessed November 13, 2018.

6. Dubois RW. CVS to restrict patient access using cost-effectiveness: too much, too soon. Health Affairs Blog. September 17, 2018. Available at: https://www.healthaffairs.org/do/10.1377/hblog20180913.889578/full/. Accessed November 13, 2018.

7. White N, Latch E, Johns A, Pace M, Stevens C. Manufacturer perspectives of ICER: impact on payers. Poster presented at: Academy of Managed Care Pharmacy Nexus 2018; October 23-25, 2018; Orlando, FL.

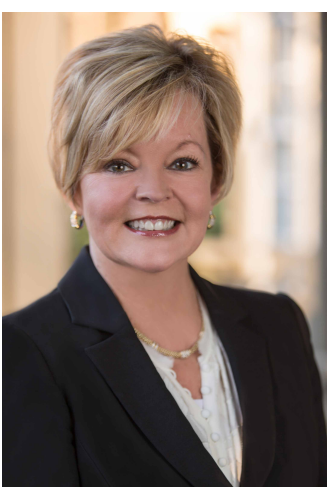

I $\mathrm{n}$ the national debate over rising health care costs, there is near universal agreement on the need to reward services and technologies that deliver value to patients and the health care system. The Academy of Managed Care Pharmacy (AMCP) has long supported the shift from fee-forservice, volume-based payment to a value-based system. To facilitate this shift, AMCP endeavors to provide information, education, and advocacy on the topic of value as it relates to managed care pharmacy. In fact, a quick search of the JMCP website reveals hundreds of articles just in the last few years that encompass value and value assessment. Toward the goal of a value-based health care system, the new JMCP series Perspectives on Value is being launched.

Any discussion of value in health care inevitably leads to questions about value assessment. What methods are valid for assessing value in health care? Who gets to decide what value is? How should value be rewarded in our system of constrained resources? The path to clarity on these and other questions about value assessment will no doubt be characterized by robust dialogue and scientific debate. We have seen this debate take hold as various frameworks and groups that assess value, including ICER, have emerged in the United States and ignited disagreement over value assessment.

While there is ongoing debate over the process of value assessment and how to apply benchmarks such as those provided by ICER, there is a need to have these challenging discussions. This need is driven, in part, by scientific advances and the many innovative therapies that come to market each year. These therapies have the potential to improve the quality of care, or even potentially provide cures, for many diseases and conditions. Yet these therapies often come with high costs that must be managed in an environment of limited resources. As such, publication of ICER summaries and companion commentaries in JMCP gets to the very heart of managed care pharmacy's focus on advancing value in health care.

We are proud of AMCP's long track record of convening diverse health care stakeholders to address difficult challenges, and we see this new series in the same light. As health care professionals, we all share the same goal-to use sound scientific evidence to achieve optimal outcomes for our patients while ensuring efficient use of resources. Sharing these articles brings us a step closer to realizing that kind of value-based care system.

Susan A. Cantrell, RPh, CAE AMCP CEO, JMCP Publisher 